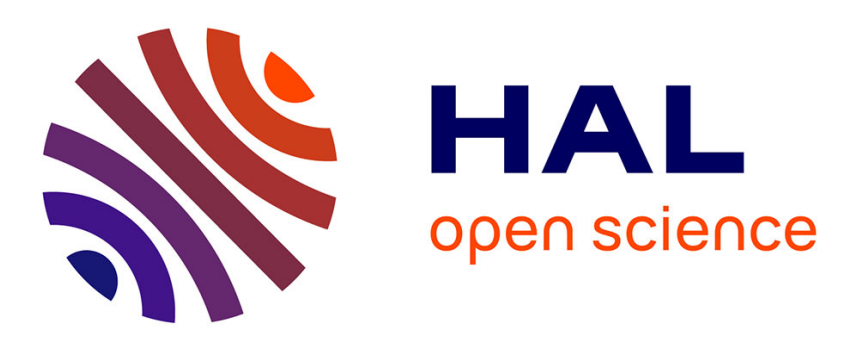

\title{
Cost functions are nonconvex in the outputs when the technology is nonconvex: convexification is not harmless
}

Kristiaan Kerstens, Ignace van de Woestyne

\section{To cite this version:}

Kristiaan Kerstens, Ignace van de Woestyne. Cost functions are nonconvex in the outputs when the technology is nonconvex: convexification is not harmless. Annals of Operations Research, 2021, 305, pp.81-106. 10.1007/s10479-021-04069-1 . hal-03274911

\section{HAL Id: hal-03274911 \\ https://hal.science/hal-03274911}

Submitted on 4 Jan 2022

HAL is a multi-disciplinary open access archive for the deposit and dissemination of scientific research documents, whether they are published or not. The documents may come from teaching and research institutions in France or abroad, or from public or private research centers.
L'archive ouverte pluridisciplinaire HAL, est destinée au dépôt et à la diffusion de documents scientifiques de niveau recherche, publiés ou non, émanant des établissements d'enseignement et de recherche français ou étrangers, des laboratoires publics ou privés. 


\title{
Cost Functions are Nonconvex in the Outputs when the Technology is Nonconvex: Convexification is Not Harmless*
}

\author{
Kristiaan Kerstens, Ignace Van de Woestyne $e^{\ddagger}$
}

August 10, 2020

\begin{abstract}
This contribution focuses on testing the empirical impact of the convexity assumption in estimating costs using nonparametric specifications of technology and cost functions. Apart from reviewing the scant available evidence, the empirical results based on two publicly available data sets reveal the effect of the convexity axiom on cost function estimates: cost estimates based on convex technologies turn out to be on average between $21 \%$ and $38 \%$ lower than those computed on nonconvex technologies. These differences are statistically significant when comparing kernel densities and can be illustrated using sections of the cost function estimates along some output dimension. Finally, also the characterization of returns to scale and economies of scale using production and cost functions for individual units yields conflicting results for between $19 \%$ and $31 \%$ of individual observations. The theoretical known potential impact as well as these empirical results should make us reconsider convexity in empirical production analysis: clearly, convexity is not harmless.
\end{abstract}

JEL CODES: D24

Keywords: Data Envelopment Analysis; Economics; Technology; Cost analysis

${ }^{*}$ We acknowledge the most helpful comments of G. Cesaroni, P. Kerstens, F. Maier-Rigaud and M. Vardanyan on earlier versions. We thank conference and seminar participants in Auckland, Berlin, Bordeaux, Edinburgh, Harbin, Helsinki, Houston, Palmerston North, Rennes, Shanghai, Taipei, Tehran and Tianjin for useful comments on earlier drafts. We are most grateful to three referees of this journal. The usual disclaimer applies. Note that this contribution has circulated under different titles.

${ }^{\dagger}$ Corresponding author: IESEG School of Management, CNRS, Univ. Lille, UMR 9221-LEM, 3 rue de la Digue, F-59000 Lille, France, Tel: +33 320545892 (switchboard), Fax: +33 320574855, k.kerstens@ieseg.fr

${ }_{\ddagger}^{\ddagger} \mathrm{KU}$ Leuven, Research Unit MEES, Brussels, Belgium, ignace.vandewoestyne@kuleuven. be 


\section{Introduction}

The empirical analysis of production technologies or its related value functions (e.g., cost functions) are standard methods in the empirical toolbox of the applied economist. The empirical studies analysing economies of scale, elasticities of substitution, efficiency, productivity and other economic phenomena of interest serve a wide variety of academic, regulatory and managerial purposes. The traditional parametric, semi-parametric and nonparametric specifications of technologies and value functions habitually maintain the convexity axiom.

It is well-known that a variety of reasons may generate nonconvexities in technology (see Farrell (1959) for an early overview). One example is indivisibilities: the fact that inputs and outputs in production are not perfectly divisible and thus cannot be varied continuously (see Scarf (1986; 1994)). Furthermore, indivisibilities limit the up- and especially the downscaling of production processes. In addition, economies of scale and economies of specialization (see, e.g., Romer (1990) on nonrival inputs in the new growth theory) as well as externalities are all well-known features violating the convexity of technology. Also the aggregation of well behaved distinct technologies (in the sense of blueprint books) may give rise to some local nonconvex range (see Hung, Le Van, and Michel (2009)). Nonconvexities create issues about the role of prices in defining equilibria (e.g., Scarf (1986)). Forceful statements about the importance of nonconvexities in modern production technologies are found in, e.g., the work of Scarf (1994, p. 115) who states: "the essence of economies of scale in production is the presence of large and significant indivisibilities in production. What I have in mind are assembly lines, bridges, transportation and communication networks, giant presses and complex manufacturing plants, which are available in specific discrete sizes, and whose economic usefulness manifests itself only when the scale of operation is large." Also Eaton and Lipsey (1997) argue that the very existence of capital goods with a lump of embodied services (rather than disembodied service flows) points to fundamental nonconvexities in production.

Nevertheless, in empirical production analysis these features have been ignored and convexity maintained because of the assumption of time divisibility (e.g., Shephard (1970)), or simply because of analytical convenience. Of course, if time is less than perfectly divisible, then also these other features can no longer be ignored and nonconvexities may well matter. Furthermore, it is -implicitly or explicitly- assumed that there is no impact of nonconvexities on the estimates of the parameters of interest in production and, e.g., cost approaches alike. Our basic contention is that the eventual impact of convexity on production and especially cost estimates has rarely if ever been explicitly tested in the empirical economic literature. Therefore, convexity can only be maintained if there is enough evidence that its impact on the majority of empirical applications is negligible. One cannot

just assume that the impact of convexity on technology and cost function estimates is negligible since information on how well convex cost functions approximate nonconvex ones is missing. In the remainder, a cost function with respect to a convex/nonconvex technology is referred to as a convex/nonconvex cost function. 
Therefore, the aim of this contribution is threefold. First, we summarise the limited number of studies that implicitly or explicitly tested for the impact of convexity on the cost function. Second, we empirically explore and test for the differences between estimates based on convex and nonconvex cost functions at the sample level using secondary data sources (to allow for replication), thereby focusing on the consequences for one key economic parameter of interest. In particular, the eventual differences between the characterization of economies of scale and returns to scale for convex as well as nonconvex cost functions and technologies are illustrated. This focus on scale economies and returns to scale allows to explore whether the eventual differences between convex and nonconvex cost functions have consequences for economic parameters beyond an eventual mere scaling effect. Third, these differences are also numerically illustrated with graphical sections and a count of change points relating convex and nonconvex cost estimates to the outputs for individual observations. To the best of our knowledge, the combination of these three aims is unique and did -to the best of our knowledge- nowhere appear in the literature.

These convex and nonconvex cost functions are estimated using nonparametric specifications for two reasons. First, there do not seem to exist alternative semi-parametric or parametric specifications that easily allow for testing convexity. Second, this nonparametric approach coincides with the nonparametric nature of the axioms under scrutiny. Or, as Fuss, McFadden, and Mundlak (1978, p. 223) state: "Given the qualitative, non-parametric nature of the fundamental axioms, this suggests that the more relevant tests will be non-parametric, rather than based on parametric functional forms, even very general ones."

Section 2 defines the technology and the cost function in general and also elaborates on the logical and empirical reasons to question the convexity assumption in both a production and cost context. Section 3 develops the empirical methodologies in detail: (i) the specific convex and nonconvex production and cost models to be estimated, (ii) how to plot sections of these cost functions and to count change points, and (iii) the methods to characterize returns to scale and economies of scale for individual observations in a convex and nonconvex setting. The method proposed to analyse economies of scale in a nonconvex (non-differentiable) setting is new in the literature. Next, Section 4 discusses the two data sets employed in the empirical application. Following the structure of Section 3, Section 5 presents all empirical results. Section 6 concludes.

\section{Technology and Cost Functions: Role of Convexity}

\subsection{Technology and Cost Function: Definitions and Duality}

Denoting an $n$-dimensional input vector $x \in \mathbb{R}_{+}^{n}$ and an $m$-dimensional output vector $y \in \mathbb{R}_{+}^{m}$, the production possibility set or technology $T$ is defined as follows: $T=\left\{(x, y) \in \mathbb{R}_{+}^{n} \times \mathbb{R}_{+}^{m}, x\right.$ can produce $\left.y\right\}$. The input set associated with $T$ denotes all input vectors $x$ capable of producing a given output 
vector $y: L(y)=\left\{x \in \mathbb{R}_{+}^{n}:(x, y) \in T\right\}$.

Technology satisfies some combination of the following conventional assumptions:

(T.1) $(0,0) \in T$ and if $(x, y) \in T$ and $x=0 \Rightarrow y=0$.

(T.2) $T$ is a closed subset of $\mathbb{R}_{+}^{n} \times \mathbb{R}_{+}^{m}$.

(T.3) If $(x, y) \in T$ and $\left(x^{\prime}, y^{\prime}\right) \in \mathbb{R}_{+}^{n} \times \mathbb{R}_{+}^{m}$, then $\left(x^{\prime},-y^{\prime}\right) \geq(x,-y) \Rightarrow\left(x^{\prime}, y^{\prime}\right) \in T$.

(T.4) $(x, y) \in T \Rightarrow \delta(x, y) \in T$ for $\delta \in \Gamma$, where:

(i) $\Gamma \equiv \Gamma^{\mathrm{CRS}}=\{\delta: \delta \geq 0\}$;

(ii) $\Gamma \equiv \Gamma^{\mathrm{NDRS}}=\{\delta: \delta \geq 1\}$;

(iii) $\Gamma \equiv \Gamma^{\mathrm{NIRS}}=\{\delta: 0 \leq \delta \leq 1\}$;

(iv) $\Gamma \equiv \Gamma^{\mathrm{VRS}}=\{\delta: \delta=1\}$.

(T.5) $T$ is convex, i.e., for all $\left(x_{1}, y_{1}\right) \in T,\left(x_{2}, y_{2}\right) \in T, \lambda \in[0,1]: \lambda\left(x_{1}, y_{1}\right)+(1-\lambda)\left(x_{2}, y_{2}\right) \in T$.

Traditional axioms on technology include: (i) inaction is feasible, and there is no free lunch, (ii) closedness, (iii) free disposal of inputs and outputs, (iv) returns to scale assumptions (i.e., constant returns to scale (CRS), nondecreasing returns to scale (NDRS), nonincreasing returns to scale (NIRS), and variable returns to scale (VRS)), and (v) convexity of technology (see, e.g., Färe (1988), Hackman (2008) or Ray (2004) for details). Key assumptions distinguishing some of the technologies in the empirical analysis are convexity and CRS.

While axioms $(T .1)-(T .2)$ are considered regularity conditions, the other axioms are debatable. Free disposal or monotonicity precludes phenomena like congestion to become visible. Monotonicity violations are known to affect duality relations (see Barnett (2002)) and occur rather often (see, e.g., Sauer (2006) for a review). A sharp criticism of the CRS hypothesis is found in Scarf (1994). In this contribution, CRS as well as NIRS and NDRS technologies are auxiliary to measuring returns to scale and economies of scale (details are discussed in Subsection 3.3). Finally, several reasons to doubt convexity are discussed in Subsections 2.2 and 2.3 .

Note that every technology $T^{N C}$ not satisfying the convexity axiom (T.5) can be extended to a convex technology $T^{C}$ by taking the convex hull. This convexified technology is defined by $T^{C}=\left\{\lambda\left(x_{1}, y_{1}\right)+(1-\lambda)\left(x_{2}, y_{2}\right) \mid \forall\left(x_{1}, y_{1}\right) \in T^{N C}, \forall\left(x_{2}, y_{2}\right) \in T^{N C}, \forall \lambda \in[0,1]\right\}$.

The input distance function completely characterizes the input set $L(y)$ and is defined as follows:

$$
D_{i}(x, y \mid T)=\max \{\lambda: \lambda \geq 0,(x / \lambda, y) \in T\}=\max \{\lambda: \lambda \geq 0, x / \lambda \in L(y)\} .
$$

Its main properties are: (i) $D_{i}(x, y \mid T) \geq 1$, with efficient production on the boundary (isoquant) of $L(y)$ represented by unity; (ii) it has a cost interpretation (see, e.g., Färe (1988) or Hackman 
(2008)). The inverse of the input distance function $E_{i}(x, y \mid T)=\left[D_{i}(x, y \mid T)\right]^{-1}$ determines the radial input efficiency measure. If $\delta^{*}=E_{i}(x, y \mid T)$ for some observation $(x, y) \in T$, then $\left(\delta^{*} x, y\right) \in T$ is referred to as the optimal projected point in the input direction.

Turning to a dual representation of technology, the cost function is defined as the minimum expenditures to produce an output vector $y$ given a vector of semi-positive input prices $\left(w \in \mathbb{R}_{+}^{n}\right)$ :

$$
C(y, w \mid T)=\min \{w x:(x, y) \in T\}=\min \{w x: x \in L(y)\} .
$$

Duality relations link primal and dual formulations of technology. Duality allows a well-behaved technology to be reconstructed from the observations on cost minimizing producer behavior, and the reverse. Following (Hackman, 2008, p. 114) the duality between input distance function (1) and cost function (2) is:

$$
\begin{aligned}
D_{i}(x, y \mid T) & =\min _{w}\{w x: C(y, w \mid T) \geq 1\}, x \in L(y) \\
C(y, w \mid T) & =\min _{x}\left\{w x: D_{i}(x, y \mid T) \geq 1\right\}, w>0 .
\end{aligned}
$$

Traditionally, such duality relation is established under the hypothesis of a convex input set solely (see Färe (1988, p. 84), Hackman (2008, p. 114-116: Theorem 7.15), or Jacobsen (1970, p. 760, 768 ) for details): this is a weaker version of (T.5). Traditional cost functions estimated on a convex (T.5) technology then clearly impose more structure than strictly required by duality. By contrast, the Weak Axiom of Cost Minimisation (WACM) is a consistency test for cost minimization that only imposes strong disposal of inputs and outputs (Varian (1984, p. 580-582)). Briec, Kerstens, and Vanden Eeckaut (2004) are among the first to establish a local (instead of global) duality result between nonconvex technologies that only impose strong disposal and obey different scaling laws and the corresponding nonconvex cost functions. Note that Ray (2004) shows that the basic nonconvex cost function is equivalent to WACM. It remains an open question whether the traditional cost functions estimated on convex (T.5) technologies are different from these nonconvex cost functions.

\subsection{Logical Arguments Questioning Convexity}

A logical critique of the convexity assumption can consider a variety of arguments.

First, there are some properties of the cost function in the outputs worthwhile spelling out. Some seminal contributions to axiomatic production theory indicate that the cost function is nondecreasing and convex (nonconvex) in the outputs when convexity of technology is assumed (rejected) (e.g., Jacobsen (1970, Proposition 5.2) or Shephard (1970, p. 227)). ${ }^{1}$ This property of the cost function is

\footnotetext{
${ }^{1}$ The same reasoning applies to the revenue function and all variations of the profit function, except of course the long run profit function where the effect of convexity or not cannot logically be distinguished.
} 
ignored in most advanced micro-economic textbooks (see Mas-Colell, Whinston, and Green (1995, p. 141), but see Kumbhakar and Lovell (2000, p. 34) for an exception). This empirical property has to our knowledge never been explicitly tested and has been sharpened by Briec, Kerstens, and Vanden Eeckaut (2004) who establish that (i) cost functions estimated on convex technologies yield lower or equal cost estimates compared to cost functions estimated on nonconvex technologies; and (ii) both types of cost functions are only identical for the single output and CRS case:

Proposition 2.1 (Briec, Kerstens, and Vanden Eeckaut (2004, p. 171)). Cost functions with respect to a nonconvex technology $T^{N C}$ and its convexified technology $T^{C}$ satisfy the following properties:

(a) in general: $C\left(y, w \mid T^{C}\right) \leq C\left(y, w \mid T^{N C}\right)$ for a given $\Gamma$;

(b) in the case of $\Gamma=\Gamma^{\mathrm{CRS}}$ and a single output: $C\left(y, w \mid T^{C}\right)=C\left(y, w \mid T^{N C}\right)$.

These properties of the cost function have been ignored in most if not all empirical studies.

Second, the motivation to maintain the convexity axiom is either analytical convenience (e.g., Hackman (2008, p. 2)), or time divisibility. Indeed, Hackman (2008, p. 39), Jacobsen (1970, p. 759) and Shephard (1970, p. 15) interpret convexity of technology solely in terms of time divisibility of technologies and see no other justification for its use. This time divisibility argument ignores setup and lead times that make switching between the underlying activities costly. The empirical evidence on the relevance of setup times in industrial scheduling activities is vast (see Allahverdi, $\mathrm{Ng}$, Cheng, and Kovalyov (2008) for a recent survey). Recent studies on the time allocation between different, progressively assigned projects reveal that task juggling in services is widespread despite its induced productivity losses (e.g., Coviello, Ichino, and Persico (2014)). While call setup times seem negligible today, minor alleged differences in communication speeds between participants are at the heart of academic and policy discussions on the role of high frequency trading in today's financial markets (e.g., Savani (2012)). ${ }^{2}$ Thus, perfect time divisibility is a questionable assumption that ideally needs empirical validation. While all reasons commonly advanced to explain nonconvexities in production are features of the real economy, these can be ignored when modeling production and costs if and only if time is perfectly divisible. If the time dimension is imperfectly divisible, then these other reasons for nonconvexities exacerbate this time indivisibility and it is an open question to which extent nonconvexities can be ignored in the empirical modeling of production and costs.

Third, note that the exact nature of the duality results does not make a difference. Even if duality between distance and cost function is established under convexity of the input set only as in Varian (1984) (rather than a convex technology) and one employs corresponding empirical methodologies only imposing convexity of the input sets, then the above arguments remain valid: if convexity of technology is implausible, then this also applies to any form of partial convexity. In

\footnotetext{
${ }^{2}$ Budish, Cramton, and Shim (2014) claim that the current defects in market microstructure are linked to a continuous-time market design based on a continuous limit order book. Instead, they propose a discrete-time frequent batch auction.
} 
particular, time divisibility is inconceivable as a legitimation of partial convexity since it applies to the underlying production activities: time divisibility of the input vectors independent of the resulting output vectors (or the reverse) makes little sense. By Occam's razor, we adopt the simplest theory and question convexity entirely. ${ }^{3}$ Obviously, a nonconvex or a convex input set yield the same cost function (see Varian (1984)), ${ }^{4}$ but a nonconvex or a convex output set (or technology) would not yield the same cost function, as indicated by the above properties of the cost function.

Finally, sometimes convexity is not considered a primitive axiom, but it is implied by additivity and divisibility. But, additivity and divisibility do not only imply convexity, but also CRS. This CRS assumption is at odds with indivisibilities and the lower bounds on the scaling of almost all production processes (see supra and Scarf (1994) for a sharp critique). ${ }^{5}$

\subsection{Empirical Arguments Questioning Convexity}

While nonconvexities are often mentioned in economic theories, evidence on its incidence on production and cost estimates is relatively rare. We here draw on two different empirical literatures providing some evidence as to its existence. Among the exceptions, one can either mention an abundant amount of studies from the specialised engineering literature, or a very limited amount of studies published in the economic literature.

First, the empirical evidence on engineering cost estimates available on some sectors (e.g., electricity generation) points to a nonnegligible impact of convexity in principle. For instance, nonconvexities in electricity generation due to minimum up and down time constraints, multi-fuel effects, etc. leading to nonconvex and nondifferentiable variable costs are amply documented in,

\footnotetext{
${ }^{3}$ Bogetoft, Tama, and Tind (2000) is the first article maintaining convexity on input and output space, but relaxing convexity in the graph of technology without restrictions on the dimensionality of input and output spaces. Li (2019) adds variable returns to scale to this quasiconcavity of production, but only manages to treat the single output case. This framework is justified by appeal to, for instance, the law of diminishing marginal rates of substitution in inputs space, or to the idea of diminishing marginal rates of transformation in outputs space. But, one may question whether there really is a law of diminishing marginal rates of substitution in inputs space. For example, Brokken (1977) summarises three studies revealing that there are increasing marginal rates of substitution of grain for roughage in beef production: thus, establishing nonconvexities in input space.

${ }^{4}$ Just as a nonconvex or a convex technology yields the same profit function. This implies that convexity cannot logically be tested using the profit function (even though any variation on the long-run profit function would allow testing for convexity).

${ }^{5}$ If one is willing to accept CRS, then the plausibility of additivity and divisibility separately is at stake. First, perfect divisibility of inputs and/or outputs is probably the most debatable assumption. Many if not most operations management problems in industry and distribution involve some form of indivisibilities and input fixities resulting in complex integer and possibly nonlinear optimization problems. In general, all production processes seem to have some lower limit below which a process cannot possibly be scaled down realistically. Therefore, divisibility is highly questionable (see Scarf (1994) or Winter (2008) for more detailed criticisms). Second, while additivity is essential to define free entry and may seem plausible at first, it is not beyond criticism since it presupposes spatial separation and noninteraction (see Winter (2008)). Since additivity relates to the aggregation of results of activities occurring in geographically distinct places, transportation costs must be small in order to be safely ignored. When activities are close for transportation costs to be negligible, then the risk of production externalities looms when activities get "too close" to create interactions. Furthermore, location is important in the definition of quite some outputs (e.g., Italian and Californian lemons are considered different).
} 
e.g., Bjørndal and Jörnsten (2008). However, comparisons with convex estimates are unknown to us. Seemingly, nonconvex models are a necessity and such comparisons have no use for engineers.

Second, in the economic literature one can distinguish between production and cost studies investigating convexity. Though less relevant for our purpose, there is slightly more evidence on the impact of the convexity axiom on technology-related estimates. Therefore, we briefly summarise some evidence drawn from several streams in the production literature.

First, Kerstens and Managi (2012) analyze technical change in a large panel of oil field petroleum data using a Luenberger productivity indicator: they report substantial productivity differences depending on whether convex or nonconvex technologies are used in the estimation and find only under nonconvexity that initial poor productivity fields experience faster growth than initial high productivity fields ( $\beta$-convergence) and a reduction in the dispersion of productivity levels $(\sigma$ convergence). More or less in a similar vein Alam and Sickles (2000), for instance, examine time series data on the convergence of nonconvex technical efficiency in the US airline industry.

Second, another literature offering indications on nonconvexities are parametric production studies using flexible functional forms and testing for the satisfaction of monotonicity and/or curvature conditions. If curvature or monotonicity conditions are violated, then standard second-order conditions for optimizing behavior fail to hold and duality relations break down (e.g., Barnett (2002)). Sauer (2006) revisits eight parametric frontier studies in agriculture. Apart from monotonicity violations, he finds evidence of violations of the law of diminishing marginal productivity for one to four of the maximally eight considered inputs. Furthermore, none of the estimated production frontiers fulfills the curvature criterion of quasi-concavity. One interpretation of these curvature failures is that these reveal the existence of nonconvexities.

Furthermore, it is widely acknowledged that many operations management problems in industry and distribution involve some form of indivisibilities requiring integer optimization. These technology-related findings are not surprising and are reminiscent of arguments made by engineering production function advocates stating that most production processes only under strict conditions result in well-behaved neo-classical technologies (see Wibe (1984)).

Turning now to cost studies, the evidence is rather scarce. Apart from some scant evidence on the relevance of nonconvexities in cost function estimates (e.g., Hasenkamp (1976) reporting economies of scale, and also economies of specialization for flexible enough functional forms, or Izadi, Johnes, Oskrochi, and Crouchley (2002) who report estimates compatible with a nonconvex iso-cost output possibility set), to our knowledge few studies have documented any differences between convex and nonconvex cost estimates. ${ }^{6}$ A to the best of our knowledge new and complete list of cost studies testing convexity is provided in Table 1 . While the first column contains the author(s), the second column lists the percentage difference between nonconvex and convex costs relative to nonconvex

\footnotetext{
${ }^{6}$ The Hasenkamp (1976) results are at least partially attributable to the strong assumptions on input/output separability, among others.
} 
costs (i.e., $\left.\left(C\left(y, w \mid T^{N C}\right)-C\left(y, w \mid T^{C}\right)\right) / C\left(y, w \mid T^{N C}\right)\right)$, while the third column adds some qualifying remarks. ${ }^{7}$ All studies have multiple inputs and outputs, unless otherwise indicated in the third column. Note that only few studies mention explicitly that there is an issue of convexity at stake distinguishing these results. We briefly list key results per study in alphabetic order.

We start with the studies contrasting convex and nonconvex nonparametric frontier models (see Section 3.1). Balaguer-Coll, Prior, and Tortosa-Ausina (2007) analyse Spanish local governments and report a $41.14 \%$ difference at the sample level. This study also reports this percentage for four classes in terms of population size: it monotonously decreases from $49.59 \%$ for small municipalities (population below 10000) to $13.38 \%$ (population above 20000). Briec, Kerstens, and Vanden Eeckaut (2004) study the broad-acre Western Australian agricultural sector over the period 1953 to 1987 and obtain a mild $2.24 \%$ difference at the sample level under CRS (i.e., under one of the conditions that make both results coincide). Cummins and Zi (1998) focus on 445 US life insurance companies over a balanced panel covering the period 1988-1992 and reveal a huge $49.45 \%$ difference at the sample level. These differences are also reported per year and vary between $45.65 \%$ in 1992 to $54.35 \%$ in 1988. De Borger and Kerstens (1996) report a $22.41 \%$ difference for all 589 Belgian local governments in 1985. Garbaccio, Hermalin, and Wallace (1994) report results for the US Savings and Loan industry in 1986: contrasting WACM and traditional convex cost frontiers, they find a difference of $23.46 \%$ and $22.37 \%$ for firms that remain solvent and insolvent, respectively, in the years 1988 to $1990 .{ }^{8}$ A probit analysis reveals that the nonconvex cost efficiency results yield the most accurate prediction of insolvency for both the least and the most most efficient firms. Grifell-Tatjé and Kerstens (2008) analyse both observed data and ideal engineering data for Spanish electricity distributors in 1996 and find the largest difference for the latter data, probably because engineers model an ideal grid implicitly or explicitly using nonconvex models. Narbón-Perpiñá, Balaguer-Coll, and Tortosa-Ausina (2019) also report on Spanish local governments using three models: one with compulsory minimal services, one with additional services on top of minimal services, and one with all services weighted by a quality indicator. In 2008, this leads to a $33.60 \%, 42.42 \%$ and $25.44 \%$ difference for minimal services, all services, and all services discounted with quality respectively. The same authors also report these results for the years 2009-2013, but there is not much variation over time and therefore we do not report these results. Narbón-Perpiñá, Balaguer-Coll, Petrović, and Tortosa-Ausina (2020) analyse Spanish local governments of municipalities between 1,000 and 50,000 inhabitants for the 2008-2015 period: this period leads to a $28.29 \%$ difference. Ray and Mukherjee (1995) report results for 123 US electric utilities and finds a difference of $11.02 \%$ in this single output case. Resti (1997) presents results for a panel of 270 Italian banks over the period 1988-1992 and finds a difference varying between a minimum of $20.73 \%$ and a maximum of

\footnotetext{
${ }^{7}$ While some studies offer explicit comparisons, some results in Table 1 are based on own computations. In particular, some studies report cost efficiency ratios based on cost frontier estimates under convexity and nonconvexity. Taking a ratio of these efficiency ratios nets out the observed cost and reveals the difference in cost estimates under convexity and nonconvexity.

${ }^{8}$ These authors also report results for six size classes each time for solvent and insolvent firms separately: the difference varies between a minimum of $9.38 \%$ and a maximum of $29.63 \%$.
} 
$22.98 \%$ over these years. ${ }^{9}$ Viton (2007) analyses US air carriers over the period 1970-1984 and lists a difference at the sample level of $7.29 \%$ in the single output case (i.e., under one of the conditions that make both results coincide) and $12.45 \%$ in the case of four outputs when contrasting WACM and traditional convex cost frontiers.

We end with three peculiar cases. First, Ang, Mortimer, Areal, and Tiffin (2018) compute dynamic variable profit frontiers without and with land reallocation for a balanced panel of 44 English and Welsh farms over the seven years 2007-2013 and find an average difference of $19.12 \%$ and $28.55 \%$ respectively over the years. ${ }^{10}$ Second, car manufacturing costs are known to be nonconvex due to changes in the number of shifts and in the temporary shut down of plants. Copeland and Hall (2011, p. 246) develop a specific dynamic engineering cost model of motor vehicle production in a single plant allowing for changes in price, labour and inventory stocks and report a modest $4.36 \%$ higher average nonconvex cost per vehicle compared to a convex alternative specification. Third, Ray (1997) contrasts a nonconvex nonparametric frontier cost estimate with the one resulting from a convex stochastic parametric cost frontier and reports a $24.73 \%$ difference.

One obvious conclusion from Table 1 is the percentage difference between the convex and nonconvex costs relative to nonconvex costs varies between a mild $2.24 \%$ under CRS to a huge $49.45 \%$ at the sample level. When ignoring studies applying one of the conditions that make both results coincide, this range varies between about $10 \%$ to about $54 \%$ in one particular case. The order of magnitude of these differences is large enough to justify digging deeper into this matter.

Since the vast majority of empirical approaches in production and cost analysis implicitly or explicitly maintains convexity of technology, one may conjecture that academics consider the convex approach a good approximation to a nonconvex approach. But, the quality of this approximation remains under-explored. If the studies in Table 1 are confirmed, then the true technology is nonconvex and cost function estimates on convex technologies are seriously downwardly biased.

Most studies listed in Table 1 focus on reporting results based on several methodologies. None of these studies verifies whether these different cost results lead to different conclusions with regard to key economic concepts and parameters of interest. To the best of our knowledge, our study is the first to move beyond the simple methodological contrasting of cost estimates by analysing the economic consequences in terms of returns to scale and economies of scale.

\subsection{Conclusion: Questioning Convexity}

Wrapping up, duality relations do not need a convex (T.5) technology. Cost functions differ under convexity and nonconvexity. Furthermore, convexity is not a plausible assumption since perfect

\footnotetext{
${ }^{9}$ Nonconvex results are presented graphically. Our numbers are based on information provided by the author.

${ }^{10}$ For the dynamic profit frontiers we report the difference between convex and nonconvex results relative to nonconvex results. We thank F. Ang for providing these results in personal communication.
} 


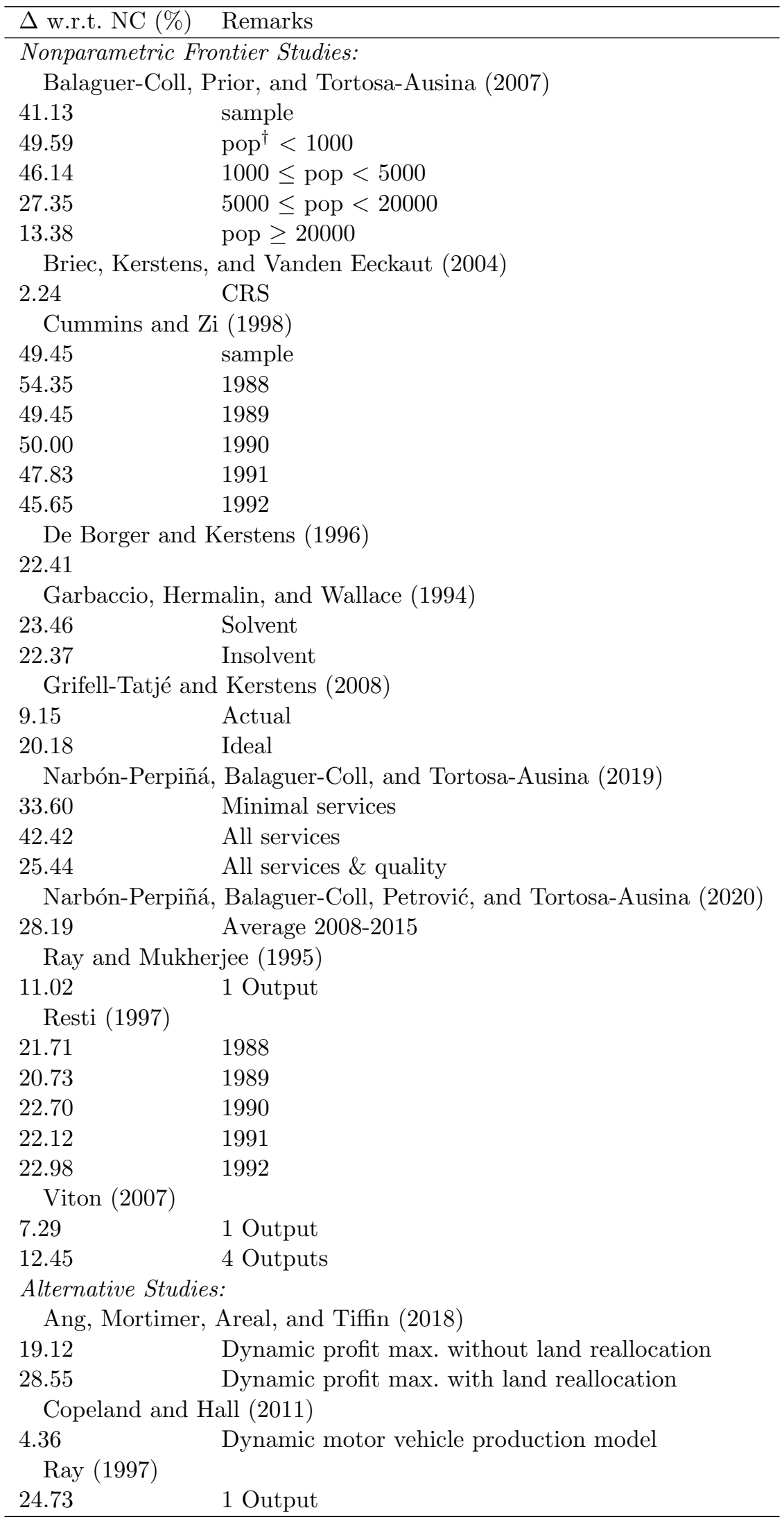

${ }^{\dagger}$ pop $=$ municipality population.

Table 1: Nonconvex and Convex fost Estimates: Literature Review 
time divisibility is questionable. Finally, the scarce empirical evidence on cost functions indicates potentially huge impacts of convexity. This needs further exploration.

\section{Empirical Methodology}

\subsection{Nonparametric Specifications of Technology and Cost Functions}

In the nonparametric approach to production theory convexity of technology is traditionally maintained (see Afriat (1972) or Diewert and Parkan (1983)). Here, we focus on the development of a nonconvex series of technologies and cost functions. Starting from a free disposal hull imposing free disposal of inputs and outputs but no convexity (see Afriat (1972) for the single output case), a first extension is the introduction of specific returns to scale assumptions into this basic model and the proposal of a new goodness-of-fit method to infer the characterization of returns to scale for nonconvex technologies (see Kerstens and Vanden Eeckaut (1999)). Another step extending the scope for nonconvex production modeling is the proposal of nonconvex cost functions with specific returns to scale assumptions (Briec, Kerstens, and Vanden Eeckaut (2004)). Some additional nonparametric, nonconvex production models are discussed in, e.g., Hackman (2008). The remainder of this subsection draws on Briec, Kerstens, and Vanden Eeckaut (2004), unless otherwise indicated.

A unified algebraic representation of convex and nonconvex technologies under different returns to scale assumptions is possible as follows:

$$
T^{\Lambda, \Gamma}=\left\{(x, y): x \geq \sum_{k=1}^{K} x_{k} \delta z_{k}, y \leq \sum_{k=1}^{K} y_{k} \delta z_{k}, z \in \Lambda, \delta \in \Gamma\right\}
$$

where

(i) $\Gamma \equiv \Gamma^{\mathrm{CRS}}=\{\delta: \delta \geq 0\}$; (ii) $\Gamma \equiv \Gamma^{\mathrm{NDRS}}=\{\delta: \delta \geq 1\}$; (iii) $\Gamma \equiv \Gamma^{\mathrm{NIRS}}=\{\delta: 0 \leq \delta \leq 1\}$; (iv) $\Gamma \equiv \Gamma^{\mathrm{VRS}}=\{\delta: \delta=1\}$;

and

(i) $\Lambda \equiv \Lambda^{\mathrm{C}}=\left\{z: \sum_{k=1}^{K} z_{k}=1\right.$ and $\left.z_{k} \geq 0\right\}$; (ii) $\Lambda \equiv \Lambda^{\mathrm{NC}}=\left\{z: \sum_{k=1}^{K} z_{k}=1\right.$ and $\left.z_{k} \in\{0,1\}\right\}$.

There is one activity vector $z$ operating subject to a nonconvexity or convexity constraint and a scaling parameter $\delta$ allowing for a particular scaling of all $K$ observations determining the technology. The activity vector $z$ of real numbers summing to unity represents the convexity axiom, while the same sum constraint with each vector element being a binary integer represents nonconvexity. This additional binary integer constraint explains why convex technologies contain their nonconvex counterparts: $T^{\Lambda^{C}, \Gamma} \supseteq T^{\Lambda^{N C}, \Gamma}$. The scaling parameter $\delta$ is free under CRS, smaller than or equal 
to 1 or larger than or equal to 1 under NIRS and NDRS respectively, and fixed at 1 under VRS. ${ }^{11}$

Computing the input distance function (1) relative to convex technologies in (5) requires solving a nonlinear programming (NLP) problem for each evaluated observation. This NLP can be easily transposed into the familiar linear programming (LP) problem that are found in the literature (see Färe (1988) or Hackman (2008)). ${ }^{12}$ For the nonconvex technologies, nonlinear mixed integer programs must be solved, but an implicit enumeration strategy is available.

Using the unified algebraic representation of the technology $T^{\Lambda, \Gamma}$ determined by (5), the cost function (2) can now be rewritten as

$$
C\left(y, w \mid T^{\Lambda, \Gamma}\right)=\min \left\{w x: x \geq \sum_{k=1}^{K} x_{k} \delta z_{k}, y \leq \sum_{k=1}^{K} y_{k} \delta z_{k}, z \in \Lambda, \delta \in \Gamma\right\} .
$$

Since convex technologies contain their nonconvex counterparts, convex cost functions are smaller than or equal to their nonconvex counterparts. In the remainder, this cost function notation is simplified to highlight either the nature of convexity or the nature of returns to scale. This equation (6) leads directly to the following lemma:

Lemma 3.1. For a given output level $y \in \mathbb{R}_{+}^{m}$ and a price vector $w \in \mathbb{R}_{+}^{n}, C(y, w \mid \mathrm{CRS})=$ $\min \{C(y, w \mid \mathrm{NIRS}), C(y, w \mid \mathrm{NDRS})\}$.

Proof. This result follows directly from the fact that $\Gamma^{\mathrm{CRS}}=\Gamma^{\mathrm{NIRS}} \cup \Gamma^{\mathrm{NDRS}}$.

Computing these cost functions relative to convex nonparametric technologies involves solving an LP per observation (see Färe (1988) or Hackman (2008)). For the cost functions relative to the nonconvex technologies, again implicit enumeration algorithms have been obtained. Note again that the VRS nonconvex cost function is equivalent to WACM.

Recalling from Proposition 2.1 that costs evaluated on nonconvex technologies are higher or equal to costs evaluated on convex technologies (except under CRS and a single output), this relation implies that if the true technology is nonconvex, then a cost function computed on a convex technology yields a downwardly biased estimate. The reverse need not hold: for a truly convex technology a cost function computed on a nonconvex technology asymptotically converges to the one computed on a convex technology.

While the above approach can be considered deterministic, since all deviations from the frontier

\footnotetext{
${ }^{11}$ Nonparametric deterministic frontier estimators that minimally extrapolate the data subject to some maintained axioms are labeled Data Envelopment Analysis (DEA) models in contrast to different (e.g., parametric) methodologies. The same moniker is also used to distinguish these convex models from the nonconvex ones in (5) that are sometimes labeled Free Disposal Hull (FDH) technologies. This use of monikers to denote both general methodologies and specific models is confusing.

${ }^{12}$ Substituting $t_{k}=\delta z_{k}$ in (5), one rewrites the sum constraint on the activity vector. Realizing that the constraints on the scaling factor are integrated into the latter sum constraint, the LP appears.
} 
are attributed to inefficiencies, several proposals are available in the literature to develop stochastic nonparametric frontier estimators. In view of the Duhem-Quine hypothesis that the empirical testing of any scientific hypothesis requires auxiliary assumptions and that in case of falsification it is difficult to single out one hypothesis responsible for its failure, we keep the amount of auxiliary assumptions to a strict minimum by sticking to the simplest of theoretical frameworks in which convexity can be tested. Therefore, our estimates combine inefficiency and measurement error. ${ }^{13}$

\subsection{Sections of Cost Functions in the Outputs}

The reconstruction and visualization of production frontiers has been the subject of a rather limited number of contributions (e.g., Hackman, Passy, and Platzman (1994) or Hackman (2008, Ch. 10)). Since traditional production possibility sets are convex polyhedra, one can enumerate their facets to reconstruct the boundaries of the set. A two-dimensional projection is then defined relative to a particular point in the technology. Krivonozhko, Utkin, Volodin, Sablin, and Patrin (2004) present a family of parametric optimization methods to construct an intersection of the multidimensional frontier with a two-dimensional plane determined by any pair of given directions.

In a similar way, for a given observation a section of a cost function along one particular output dimension with a grid of 10000 points within the empirical range of the sample for the output selected can be computed using simple parametric programming methods. We also numerically approximate for the first time in the empirical literature a count of the number of change points spanning these piecewise linear cost functions. Sections in cost-output space are -to our knowledgenew in the literature: the algorithm is described in the Appendix A.

\subsection{Characterizing Returns to Scale and Economies of Scale}

Several methods have been proposed in the literature to obtain qualitative information regarding global returns to scale. Since these methods are unsuitable for nonconvex technologies, Kerstens and Vanden Eeckaut (1999, Proposition 2) generalize an existing goodness-of-fit method to suit all technologies. With the inclusion by Podinovski (2004b) of a fourth returns to scale case only relevant for nonconvex technologies, the following proposition summarizes this method.

Proposition 3.1. Technology $T^{\Lambda, \mathrm{VRS}}$ is globally characterized at the optimal projected point in input direction $\left(\delta^{*} x, y\right)$ with $\delta^{*}=E_{i}(x, y \mid V R S)$ as follows:

(a) $C R S \Leftrightarrow E_{i}(x, y \mid N I R S)=E_{i}(x, y \mid N D R S)=E_{i}(x, y \mid V R S)$;

\footnotetext{
${ }^{13}$ Badunenko, Henderson, and Kumbhakar (2012) show that the reliability of efficiency scores of nonparametric, deterministic convex frontier estimation remains excellent when the ratio of the variation in efficiency to the variation in noise is low. Assuming this result would also be confirmed for nonconvex similar estimators and would also hold for the unexplored case of the cost function, this reinforces our argument to opt for a simple deterministic nonparametric frontier framework to test for convexity.
} 
(b) $I R S \Leftrightarrow E_{i}(x, y \mid N I R S)<E_{i}(x, y \mid N D R S) \leq E_{i}(x, y \mid V R S)$;

(c) $D R S \Leftrightarrow E_{i}(x, y \mid N D R S)<E_{i}(x, y \mid N I R S) \leq E_{i}(x, y \mid V R S)$;

(d) $S C R S \Leftrightarrow E_{i}(x, y \mid N I R S)=E_{i}(x, y \mid N D R S)<E_{i}(x, y \mid V R S)$;

where IRS, DRS and SCRS stand for increasing, decreasing and sub-constant returns to scale, respectively.

Essentially, these CRS, NIRS and NDRS technologies are auxiliary to determine the position of an observation relative to the true flexible (i.e., VRS) returns to scale technology. Note that Podinovski (2004a) convincingly shows that global and local returns to scale need not coincide under nonconvexity: for instance, when moving from an IRS towards a CRS point average productivity increases monotonously on a convex technology, but this need not hold true for a nonconvex technology. Note that the characterization in Proposition 3.1 should be considered at the optimal projected point in the input direction. Therefore, if starting from an inefficient observation, then the corresponding characterization refers to that of this corresponding optimal projected point.

We now develop a -to the best of our knowledge- new goodness-of-fit method using various cost functions to determine different economies of scale cases in a nonconvex (non-differentiable) setting. To achieve this, we first introduce the related notions of minimal ray average cost and optimal scale size in the following definition. ${ }^{14}$

Definition 3.1. For a given output level $y \in \mathbb{R}_{+}^{m}$ and a price vector $w \in \mathbb{R}_{+}^{n}$, the minimal ray average cost (RAC) with respect to technology $T$ is given by

$$
\operatorname{RAC}(y, w \mid T)=\min _{\lambda}\left\{\frac{C(\lambda y, w \mid T)}{\lambda}: \lambda>0\right\} .
$$

The optimal value of $\lambda$ realizing RAC is referred to as the optimal scale size.

The following lemma provides some relations between RAC and the cost function:

Lemma 3.2. For a given output level $y \in \mathbb{R}_{+}^{m}$ and a price vector $w \in \mathbb{R}_{+}^{n}$ :

(a) $\operatorname{RAC}(y, w \mid \mathrm{CRS})=C(y, w \mid \mathrm{CRS})$;

(b) $\operatorname{RAC}(y, w \mid \mathrm{VRS})=C(y, w \mid \mathrm{CRS})$;

(c) $\operatorname{RAC}(y, w \mid \mathrm{CRS})=\operatorname{RAC}(y, w \mid \mathrm{VRS})=C(y, w \mid \mathrm{CRS})$;

(d) $\operatorname{RAC}(y, w \mid T) \leq C(y, w \mid T)$.

\footnotetext{
${ }^{14}$ Our approach is somewhat similar to the one developed in Cesaroni and Giovannola (2015).
} 
The proof of Lemma 3.2 is in the Appendix B. Using RAC, we can now define economies of scale of the cost function for the (true) VRS technology:

Definition 3.2. For a given output level $y \in \mathbb{R}_{+}^{m}$ and a price vector $w \in \mathbb{R}_{+}^{n}$, the following economies of scale are provided for $C(y, w \mid \mathrm{VRS})$ :

(a) $\operatorname{CES}$ if $\operatorname{RAC}(y, w \mid \mathrm{VRS})$ is attained for at least the optimal scale size 1;

(b) IES if $\operatorname{RAC}(y, w \mid \mathrm{VRS})$ is attained for one or more optimal scale sizes, all of which are strictly greater than 1 ;

(c) DES if $\operatorname{RAC}(y, w \mid \mathrm{VRS})$ is attained for one of more optimal scale sizes, all of which are strictly smaller than 1 ;

(d) SCES if $\operatorname{RAC}(y, w \mid \mathrm{VRS})$ is attained for multiple optimal scale sizes, some of which are strictly larger than 1 and others are strictly smaller than 1 ,

where CES, IES, DES and SCES stand for constant, increasing, decreasing and sub-constant economies of scale, respectively.

Note again that the fourth economies of scale case is only relevant for nonconvex cost functions. These types of economies of scale are characterized by the following practical proposition:

Proposition 3.2. For a given output level $y \in \mathbb{R}_{+}^{m}$ and a price vector $w \in \mathbb{R}_{+}^{n}$, the following characterizations for economies of scale of $C(y, w \mid \mathrm{VRS})$ hold true:

(a) CES if $C(y, w \mid N I R S)=C(y, w \mid N D R S)=C(y, w \mid V R S)$;

(b) IES if $C(y, w \mid N I R S)<C(y, w \mid N D R S) \leq C(y, w \mid V R S)$;

(c) DES if $C(y, w \mid N D R S)<C(y, w \mid N I R S) \leq C(y, w \mid V R S)$;

(d) SCES if $C(y, w \mid N I R S)=C(y, w \mid N D R S)<C(y, w \mid V R S)$.

The proof of Proposition 3.2 is in the Appendix B. Observe that the structure of Proposition 3.2 is very similar to Proposition 3.1 dealing with returns to scale in production correspondences. In fact, if only one input is assumed, then the following result holds true:

Lemma 3.3. Consider a technology $T$ with only one input and, hence, one input price $w \in \mathbb{R}_{+}$. For $(x, y) \in T$, it follows that

$$
\frac{C(y, w \mid T)}{w}=x E_{i}(x, y \mid T) .
$$

The proof of Lemma 3.3 is in the Appendix B. Using this lemma, the correspondence between Propositions 3.1 and 3.2 follows directly in the case of a single input. Obviously, this relation no longer applies in the case of multiple inputs. 


\section{Description of the Samples}

We employ two secondary data sets for our empirical analysis from the Journal of Applied Econometrics Data Archive (http://qed.econ.queensu.ca/jae/). The first sample is based on 16 Chilean hydro-electric power generation plants observed on a monthly basis for several years (Atkinson and Dorfman (2009)). Limiting ourselves to the observations for the single year 1997, we can safely ignore any technical change and specify an inter-temporal frontier. This results in a total of 192 observations. There is one output quantity (electricity generated). There are also the prices and quantities of three inputs: labor, capital, and water. Except for the input capital, all remaining flow variables are expressed in physical units. Prices are in current Chilean pesos. Basic descriptive statistics for the inputs and the single output as well as more details on these data are available in Atkinson and Dorfman (2009).

The second sample is an unbalanced panel of three years (1984-1986) of French fruit producers based on annual accounting data collected in a survey (Ivaldi, Ladoux, Ossard, and Simioni (1996)). Mainly two criteria were adapted to select the farms: (i) the production of apples must be larger than zero, and (ii) the productive acreage of the orchard must be at least five acres. As a technology, three aggregate inputs are combined to produce two outputs. The three inputs are: (i) capital (including land), (ii) labor, and (iii) materials. The two aggregate outputs are (i) the production of apples, and (ii) an aggregate of alternative products. Also input prices are available in French francs. Summary statistics for the 405 observations in total and details on the definitions of all variables are available in Appendix 2 in Ivaldi, Ladoux, Ossard, and Simioni (1996). Note that the short length of the panel (only three years) justifies the use of an intertemporal approach that ignores technical change.

This choice of data sets is driven by the desire to illustrate the effects of the convexity assumption on the cost function in both the single and the multiple output cases.

\section{$5 \quad$ Empirical Results}

Recall that first we report the eventual differences between estimates based on convex and nonconvex cost functions at the sample level. Furthermore, these are illustrated with graphical sections relating costs to the outputs for some specific observations. Second, we also illustrate the eventual differences between the characterization of economies of scale and returns to scale for convex and nonconvex cost functions and technologies alike. 


\subsection{Cost Frontier Estimates: Descriptive Statistics and Testing Convexity}

Table 2 reports some basic descriptive statistics on both the convex and nonconvex cost frontier estimates on both VRS and CRS technologies. Since CRS is a strong and unrealistic assumption, the computations of the cost frontier estimates relative to CRS technologies mainly serves the purpose of illustrating Proposition 2.1. The last two columns report the difference in terms of the nonconvex estimates (i.e., $\left.\left(C\left(y, w \mid T^{N C}\right)-C\left(y, w \mid T^{C}\right)\right) / C\left(y, w \mid T^{N C}\right)\right)$, just as in the second column of Table 1. Three conclusions jump out. First, nonconvex cost frontier estimates are on average substantially higher than their convex cost counterparts, while the VRS ones are again higher than the CRS ones. The last two columns indicate that the convex estimates are on average between $20.76 \%$ and $38.08 \%$ lower in the VRS case, and between $0.00 \%$ and $25.11 \%$ lower in the CRS case. The single output sample reveals a smaller gap than the multi-output case. Second, for the hydro-power plants both nonconvex and convex results are identical for the CRS case, because of the single output. Third, while the empirical range of the VRS case is identical in the single output case, by contrast the empirical range varies substantially for the multi-output fruit producers, apart from the minimum cost on the VRS technology.

\begin{tabular}{|c|c|c|c|c|c|c|}
\hline \multicolumn{7}{|c|}{ Sample 1: Chilian Hydro-power Plants } \\
\hline \multirow[t]{2}{*}{ Costs } & \multicolumn{2}{|c|}{ Nonconvex (NC) } & \multicolumn{2}{|c|}{ Convex (C) } & \multicolumn{2}{|c|}{$\Delta$ w.r.t. NC (\%) } \\
\hline & $V R S$ & $C R S$ & $V R S$ & $C R S$ & $V R S$ & $C R S$ \\
\hline Average & 10.67 & 6.22 & 8.45 & 6.22 & 20.76 & 0.00 \\
\hline Stand.Dev. & 13.64 & 7.43 & 11.08 & 7.43 & 18.78 & 0.00 \\
\hline Minimum & 2.49 & 0.04 & 2.49 & 0.04 & 0.00 & 0.00 \\
\hline Maximum & 65.80 & 39.25 & 65.80 & 39.25 & 0.00 & 0.00 \\
\hline Li test $^{\dagger}$ & \multicolumn{4}{|c|}{ VRS $12.18^{* * *}$} & \multicolumn{2}{|c|}{ CRS 0.0} \\
\hline \multicolumn{7}{|c|}{ Sample 2: French Fruit Producers } \\
\hline Costs & \multicolumn{2}{|c|}{ Nonconvex (NC) } & \multicolumn{2}{|c|}{ Convex $(\mathrm{C})$} & \multicolumn{2}{|c|}{$\Delta$ w.r.t. $\mathrm{NC}(\%)$} \\
\hline & VRS & $C R S$ & VRS & $C R S$ & $V R S$ & $C R S$ \\
\hline Average & 1160.91 & 683.06 & 718.84 & 511.51 & 38.08 & 25.11 \\
\hline Stand.Dev. & 1730.08 & 880.89 & 1124.45 & 758.76 & 35.01 & 13.86 \\
\hline Minimum & 150.11 & 13.15 & 150.11 & 8.51 & 0.00 & 35.29 \\
\hline Maximum & 13448.40 & 6754.19 & 11815.70 & 6095.27 & 12.14 & 9.76 \\
\hline Li test $^{\dagger}$ & \multicolumn{4}{|c|}{ VRS $12.29^{* * *}$} & \multicolumn{2}{|c|}{ CRS $7.34^{* * *}$} \\
\hline
\end{tabular}

${ }^{\dagger} \mathrm{Li}$ test: critical values at $1 \%=2.33(* * *) ; 5 \%=1.64\left({ }^{* *}\right) ; 10 \%=1.28(*)$.

Table 2: Nonconvex and Convex Cost Function Estimates: Descriptive Statistics

A detailed analysis of the last two columns can furthermore reveal us something on the impact of multiple outputs and CRS in explaining the divergence between nonconvex and convex costs. In the multi-output case, the total gap between nonconvex and convex costs amounts to $38.08 \%$. The amount of $25.11 \%$ is due to the multi-output nature of production given CRS, while the residual $12.97 \%(=38.08 \%-25.11 \%)$ is due to nonconstant returns to scale. In the single output case, the total gap of $20.76 \%$ is due to nonconstant returns to scale, since the assumption of CRS would reduce the gap to $0 \%$ by definition. The differences between both data sets call for more research 
into the causes of the total cost gap.

To facilitate the appreciation of these differences in more detail we also plot kernel density estimates of all cost estimates related to the four frontier specifications per data set. Figures 1(a) and 1(b) represent the densities for most part of the observed range of cost estimates for the hydropower plants and the fruit producers respectively. ${ }^{15}$ Figure 1(a) illustrates clearly: (i) Convex and nonconvex VRS cost frontiers differ markedly in shape: the first is downwardly asymmetrical and almost uni-modal while the second is asymmetrical multi-modal. (ii) Convex and nonconvex CRS cost frontiers coincide: its distribution is about downwardly asymmetrical uni-modal. Figure 1(b) reveals downwardly asymmetrical densities for all frontiers and a markedly higher mode for the convex cases for a given returns to scale assumption.

Figure 1: Kernel Density Estimates of Cost Function Estimates for (a) Chilean Hydro-power Plants and (b) French Fruit Producers

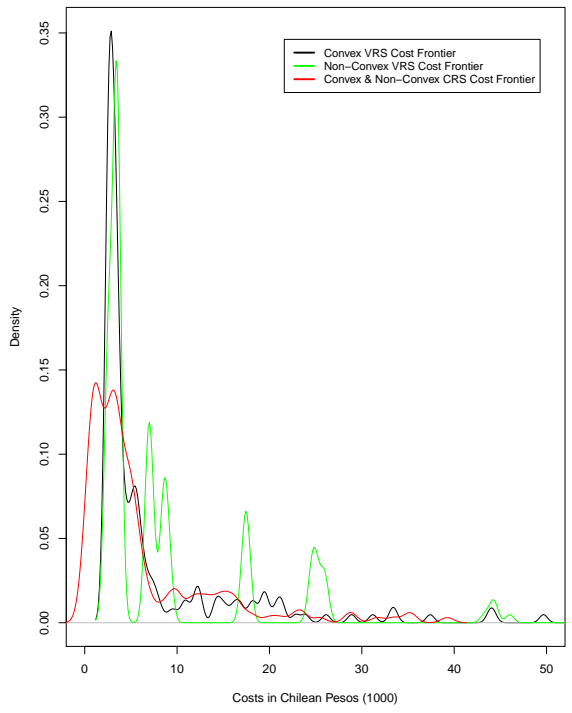

(a)

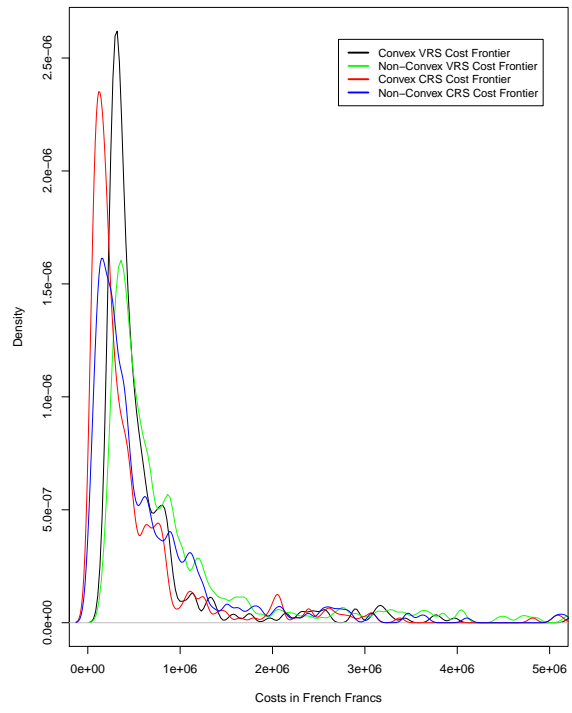

(b)

Differences between the densities of these cost function estimates can be tested with a consistent nonparametric test of closeness between two unknown density functions that is asymptotically normal distributed under the corresponding null hypothesis. This Li test statistic -proposed by Li (1996) and refined by Fan and Ullah (1999)- has an important characteristic for our purpose: it is valid for both dependent and independent variables. Dependency is distinctive for frontier estimators (e.g., efficiency depends on sample size, among others). Furthermore, it imposes the quite mild conditions that both densities are bounded and continuous (see (Fan and Ullah, 1999, Section 2)) and it works fine for moderate sample sizes above 50. The null hypothesis states the equality of both convex and nonconvex distributions of cost function estimates for a given returns to scale assumption. The bottom lines in upper and lower parts of Table 2 report the test statistics:

\footnotetext{
${ }^{15}$ To enhance comparability we use a common Sheather and Jones plug-in bandwidth for the convex and nonconvex data series to be compared.
} 
apart from the identical series for CRS and a single output, the differences in densities between convex and nonconvex series are significant.

\subsection{Sections of the Cost Function in the Outputs}

As a graphical illustration of the above sample level results, we plot convex and nonconvex cost functions for some specific observations. Figure 2(a) plots cost estimated on VRS along the single output for hydro-power plant number 16 in July 1997. Figure 3(a) plots costs estimated on VRS along the first output dimension solely for fruit producer number 19 in 1984. Figures 2(b) and 3(b) plot total costs for the same individual observations for the CRS case for the respective samples. Notice that for the single output hydro-power plants the convex and nonconvex CRS costs coincide.

Figure 2: Cost Function in the Single Output for Hydro-power Plant 16 in July 1997 (a) VRS and (b) CRS

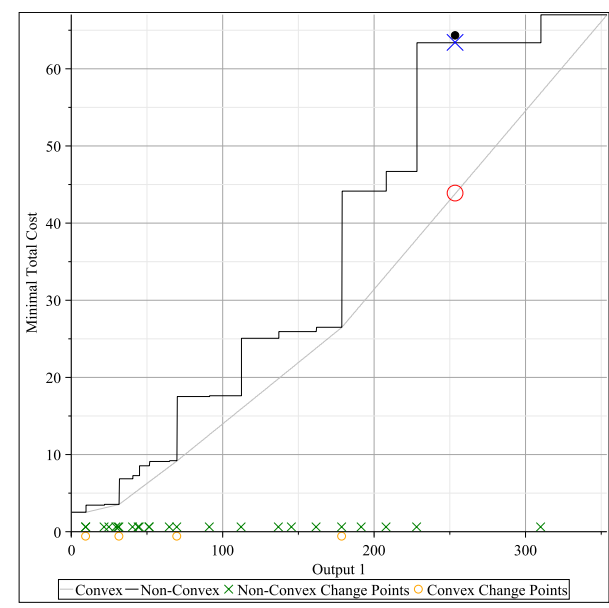

(a)

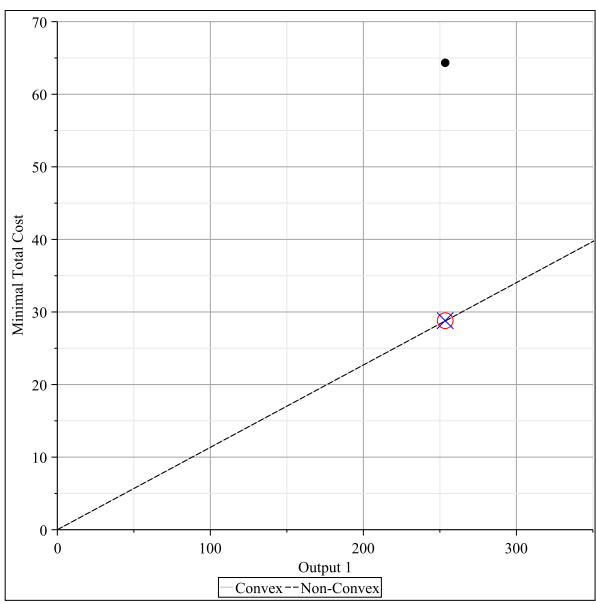

(b)

Two key observations can be made. First, while in the single output case in Figure2(a), apart from the extremes both convex and nonconvex cost functions coincide several times within the empirical range of the data, both cost functions are entirely different within the empirical range of the data in the multiple output case plotted in Figure 3(a) (again apart from the extremes). ${ }^{16}$ Second, for observations within the empirical range the nonconvex cost function always offers a substantially closer fit compared to its convex counterpart. Representing the original observation by a bullet $(\bullet)$, the nonconvex and convex projection points on the cost frontiers are indicated by a times sign $(\times)$ and circle $(\circ)$ respectively. One can observe that the difference between cost frontiers

\footnotetext{
${ }^{16}$ Indeed, in the single output case it may be intuitively clear that convex and nonconvex cost functions trace the same function at the extremes of the empirical range, but that in between the approximation depends on the precise structure of the sample. This intuition for the single output case is developed in the figures in Appendix $\mathrm{C}$ by computing the models in Section 3.1 on a numerical example with two inputs and a single output. However, the situation is less clear in the multi-output case: convex and nonconvex cost functions need not have very much in common except at some of the extremes of the empirical range (see Appendix D for figures computed on a numerical example with one input and two outputs).
} 
Figure 3: Cost Function in Output 1 for Fruit Producer 19 in 1984 (a) VRS and (b) CRS

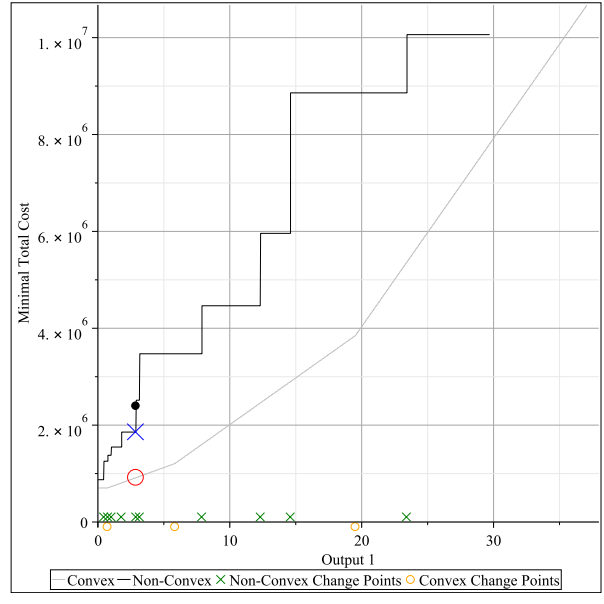

(a)

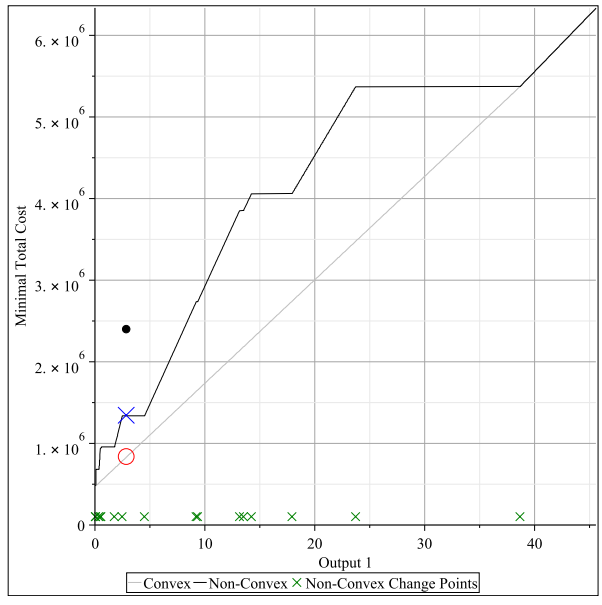

(b)

is huge in Figure2(a) for observation 16 in July 1997. This difference is slightly less pronounced for observation 19 in Figure 3(a).

For the CRS case, both projection points coincide in the single output case in Figure 2(b), but diverge in the multiple output case in Figure 3(b). Overall, this further casual evidence illustrates that convex and nonconvex costs may diverge substantially depending on the output level considered within the empirical range and the returns to scale assumption maintained.

These empirical observations may point to a difference in local and global fit between both cost functions: while the nonconvex cost function has both a good local and global fit, the convex cost function may sometimes have a good local fit but its global fit is poor. The local fit concerns the distance between the observation being analysed and its projection point on the frontier. This distance is always small for the nonconvex cost function, and it can be small or large for the convex cost function (just contrast Figures 2(a) and 3(a)).

One possible indication of the global fit is a count of the number of change points spanning the piecewise linear cost functions. For the VRS cost functions depicted in Figures 2(a) and 3(a), we count on the one hand 4 and 24, and on the other hand 3 and 10 change points for the convex and nonconvex cases, respectively. For the CRS cost functions depicted in Figures 2(b) and 3(b), one finds on the one hand 0 and 0 , and on the other hand 0 and 16 change points for the convex and nonconvex cases, respectively. The numerical procedure to determine these change points starts from a refined grid of 10000 points. Clearly, the global fit of the nonconvex cost function is way better than that of its convex counterparts.

To avoid the anecdotal nature of this evidence, Table 3 reports descriptive statistics on the number of change points for all observations in both samples. To reduce the computational burden, 
the numerical procedure determining the change points starts from a grid of 1000 points only. For the fruit producers, we report all change points along a section in the first output dimension (as depicted) as well as along a section in the second output dimension (which has not been depicted). Two observations are clear. First, under the VRS hypothesis the nonconvex sections show on average up to four times more change points compared to convexity (the CRS sections actually show even relatively more change points). Second, the situations depicted in Figures 2(a) to 3(b) clearly fall in line with these results and are not peculiar at all. This additional systematic evidence shows that convex and nonconvex cost frontier estimates are supported by a substantially different amount of observations determining these change points, depending on the returns to scale assumption.

\begin{tabular}{|c|c|c|c|c|}
\hline \multicolumn{5}{|c|}{ Sample 1: Chilian Hydro-power Plants } \\
\hline \multirow[t]{2}{*}{ Costs } & \multicolumn{2}{|c|}{ Nonconvex (NC) } & \multicolumn{2}{|c|}{ Convex $(\mathrm{C})$} \\
\hline & $V R S$ & $C R S$ & $V R S$ & $C R S$ \\
\hline Average & 19.44 & 0.00 & 4.13 & 0.00 \\
\hline Stand.Dev. & 0.71 & 0.00 & 0.34 & 0.00 \\
\hline Minimum & 19 & 0 & 4 & 0 \\
\hline Maximum & 21 & 0 & 5 & 0 \\
\hline \multicolumn{5}{|c|}{ Sample 2: French Fruit Producers } \\
\hline Costs & \multicolumn{2}{|c|}{ Nonconvex (NC) } & \multicolumn{2}{|c|}{ Convex $(\mathrm{C})$} \\
\hline Output 1 & VRS & $C R S$ & $V R S$ & $C R S$ \\
\hline Average & 13.16 & 10.74 & 4.88 & 1.92 \\
\hline Stand.Dev. & 2.94 & 2.94 & 0.95 & 0.28 \\
\hline Minimum & 0 & 1 & 0 & 1 \\
\hline Maximum & 18 & 19 & 8 & 2 \\
\hline Output 2 & $\overline{V R S}$ & $C R S$ & $V R S$ & $C R S$ \\
\hline Average & 5.95 & 9.75 & 3.69 & 0.98 \\
\hline Stand.Dev. & 2.11 & 2.92 & 1.20 & 0.13 \\
\hline Minimum & 0 & 1 & 0 & 0 \\
\hline Maximum & 10 & 20 & 6 & 1 \\
\hline
\end{tabular}

Table 3: Nonconvex and Convex Cost Function Sections: Descriptive Statistics on Change Points

Our evidence on the hydro-power plants confirms the empirical evidence on nonconvexities in electricity generation costs in the engineering literature (e.g., Bjørndal and Jörnsten (2008)). The results for the fruit production farms reveal that, even in cases where a priori nonconvexities are not anticipated to be prominent, these still may play a role and influence cost function estimates. Obviously, part of the observed differences between convex and nonconvex cost function estimates may be due to stochastic errors or the fact that technical change did occur during the respective observation periods. ${ }^{17}$ However, it remains unclear how either stochastic errors or technical change would have a differential impact on convex versus nonconvex cost functions and thereby affect the observed differences.

\footnotetext{
${ }^{17}$ Results in, e.g., Ray and Kim (1995) learn that accounting for nonregressive technical change increases technical efficiency, thereby improving the empirical fit. However, their panel data set covers a long time period, while ours have a short time dimension.
} 


\subsection{Returns to Scale and Economies of Scale Results}

Next, it is important to verify whether there exist any differences in the determination of returns to scale and economies of scale for individual observations when applying Propositions 3.1 and 3.2. Per data set and per production and cost method, we report in Table 4 the percentages of observations for which the returns and economies to scale classification coincides, as well as the ones for which these classifications diverge. For each of the four parts in Table 4, starting from the nonconvex case on the left we see the impact of moving to a convex world in the columns to the right. In each part, row totals in the last column and column totals in the last row yield the returns and economies to scale for the nonconvex and the convex cases respectively. Furthermore, we report the percentage of diagonal (labeled "Agreement") and off-diagonal (labeled "Disagreement") elements in the total reflecting the consensus and the divergences among the results.

\begin{tabular}{lrrrrrrrr}
\hline & \multicolumn{3}{c}{ Chilean Hydro-power Plants (\%) } & \multicolumn{5}{c}{ French Fruit Producers (\%) } \\
\hline Production & $C$-IRS & $C$-CRS & $C$ - $D R S$ & Total & $C$-IRS & $C$-CRS & $C$-DRS & Total \\
\hline NC-IRS & 63.54 & 0.00 & 6.77 & 70.31 & 74.07 & 0.00 & 0.00 & 74.07 \\
NC-CRS & 11.46 & 2.60 & 2.60 & 16.67 & 9.38 & 1.48 & 1.98 & 12.84 \\
NC-DRS & 1.04 & 0.00 & 11.98 & 13.02 & 6.91 & 0.25 & 5.93 & 13.09 \\
\hline Total & 76.04 & 2.60 & 21.35 & 100.00 & 90.37 & 1.73 & 7.90 & 100.00 \\
\hline Agreement & & & & 78.13 & & & & 81.48 \\
Disagreement & & & & 21.88 & & & & 18.52 \\
\hline Cost & $C-I E S$ & $C-C E S$ & $C-D E S$ & Total & $C-I E S$ & $C-C E S$ & $C$-DES & Total \\
\hline NC-IES & 46.35 & 5.21 & 0.00 & 51.56 & 73.83 & 0.00 & 0.00 & 73.83 \\
NC-CES & 0.00 & 0.52 & 0.00 & 0.52 & 1.73 & 0.25 & 0.00 & 1.98 \\
NC-DES & 21.88 & 3.65 & 22.40 & 47.92 & 17.78 & 0.00 & 6.42 & 24.20 \\
\hline Total & 68.23 & 9.38 & 22.40 & 100.00 & 93.33 & 0.25 & 6.42 & 100.00 \\
\hline Agreement & & & & 69.27 & & & & 80.49 \\
Disagreement & & & & 30.73 & & & & 19.51 \\
\hline
\end{tabular}

Table 4: Returns to Scale and Economies of Scale: Convex (C) vs. Nonconvex (NC) Models

Focusing on the row totals in the last column and column totals in the last row in Table 4 per sample for both a production- and cost-based analysis yields the following conclusions. First, the majority of hydro-power plant and fruit producer observations are subjected to IRS. One qualification is that the nonconvex cost approach for the hydro-power plants in fact indicates about an equal amount of IRS and DRS. For both the hydro-power plants and the fruit producers the nonconvex cost approach reveals a larger share of observations subject to DRS compared to the production-based analysis. Second, there are more observations with CRS under nonconvexity, except for the cost approach applied to the hydro-power plants. Despite the costs being equal under CRS and a single output, perhaps surprisingly the determination of global returns to scale leads to more observations being characterised as operating under CES under a convex relative to a nonconvex technology.

We make two further observations on the results in Table 4. First, focusing on the diagonal 
elements of this table, consensus on the classification varies between $69.27 \%$ and $78.13 \%$ for the hydro-power plants. This leaves a wide to modest margin of conflict. The consensus is more stable for the fruit producers across production- and cost-based analysis. Moreover, for both samples consensus is highest for the production approach. Second, turning to conflicting information, the extreme case of conflict among the off-diagonal elements is obviously the switch from increasing returns (economies) to scale to decreasing returns (diseconomies) to scale, or the reverse. For the hydro-power plants, this varies from an almost negligible $7.81 \%(=1.04 \%+6.77 \%)$ to an impressive $21.88 \%(=21.88 \%+0.00 \%)$ of cases for the production and the cost approaches respectively. The amount of conflict among the fruit producers is also quite substantial: it ranges between a mild $6.91 \%$ in production to a more pronounced $17.78 \%$ in the cost approach.

\section{Conclusions}

The main focus of this paper has been empirical rather than methodological: is convexification of nonparametric cost function estimates harmless, or does it create a bias. We think the global answer to this question has been that convexification is harmful.

Using data on Chilean hydro-power plants as well as French fruit producers, this contribution is the first to empirically illustrate the differences between convex and nonconvex cost frontier estimates and their resulting distributions, and to explore the effects on returns to scale and economies of scale. For these specific samples, convex cost functions may yield potentially downwardly biased estimates in the order between $0.00 \%$ and $38.08 \%$ depending on returns to scale hypothesis and the single vs. multi-output case. While these bias estimates may seem high, these numbers are in line with the scant evidence available in the literature: Table 1 even reports substantially higher biases. Not only are the resulting distributions of the cost estimates different at a statistically significant level, some sections of costs along a single output dimension have served to further illustrate that these differences can be huge for individual observations situated within the empirical range (not at its extremes). The sample of hydro-power plants also illustrates the result that convex and nonconvex cost functions coincide under CRS and a single output. A more systematic exploration of the number of change points supporting these empirical sections of costs along an output dimension reveals that nonconvex sections are spanned by substantially more points than convex sections.

Furthermore, differences between the characterization of economies of scale and returns to scale based on convex and nonconvex technology and cost function estimations have been highlighted. This characterization of both economies of scale and returns to scale for individual observations turns out to be conditioned by convexity in a nonnegligible way. In particular, for both samples consensus on returns to scale and economies of scale is highest for the production approach.

If cost estimates and the characterization of economies of scale and returns to scale for individual

observations turn out to be conditioned by the convexity assumption, then this may have important 
consequences. For one, investment decisions to increase or decrease the scale of operations based on economies of scale or returns to scale information could be responding to the wrong signals. For another, some capacity notions are very closely linked with the notion of scale economies and therefore would suffer from the same problem. For instance, economic capacity as defined by Klein (1960), among others, considers the outputs determined by the minimum of the long run average total costs as a reference to determine practical capacity utilization ratios. The study by Kerstens, Sadeghi, and Van de Woestyne (2019) provides some first evidence that convex and nonconvex capacity concepts tend to differ. Equally so, it is conceivable that the measurement of economies of scope and economies of specialisation is affected by the impact of convexity on the cost function (see, e.g., the framework developed by Oude Lansink, Stefanou, and Kapelko (2015)). Thus, our findings have potentially important consequences for investment decisions, definitions of capacity utilization notions, and other key economic notions.

Furthermore, the use of convex cost estimates in price cap regulation may well be too harsh in sectors where nonconvexities play a major role (e.g., electricity generation and distribution). Given the better fit of nonconvex cost estimates, for the resulting efficiency requirements to have some bite it may well become necessary to either increase the geographical scope of samples, or increase the frequency of observations. The former solution is sometimes developed by international coordination in regulatory practices (see, e.g., Estache, Rossi, and Ruzzier (2004)). Conditional upon the availability of engineering models, one can also substitute or complement existing data with so-called pseudo-data to obtain larger sample sizes (see Griffin (1979)). ${ }^{18}$ Such engineering benchmarks or normative models (based on engineering production and cost models) are in fact used in several countries (e.g., Chile, Spain and Sweden).

Therefore, it seems important to empirically explore these differences between estimates based on convex and nonconvex technologies and cost functions further in even greater detail (e.g., also focusing on economies of scope, the impact on mergers and acquisitions, the effect on marginal cost relationships, etc.). In addition, it may be envisioned to set up simulation studies to further explore the impact of the convexity assumption on technologies and cost functions alike. In conclusion, even though theoretically the impact of convexity has been known since some time, it seems to be important to further explore the effects of convexity on key economic value relations in practice. Some first evidence has been provided that the impact is nonnegligible and that convexification is not harmless for the cost function.

An open question is to what extent existing empirical methodologies need to be re-examined to be able to cope with nonconvexities: given the local nature of some of the results (e.g., the potential differences between global and local returns to scale (see Podinovski (2004a)), new standards may need to be established. For instance, Scarf (1986) associates to each feasible point a neighbourhood

\footnotetext{
${ }^{18}$ This proposal related to the engineering economics literature is not without criticism (see Maddala and Roberts (1981)). More recently, Preckel and Hertel (1988) propose a linear program summary functions method (LPSF) that is equivalent to the pseudodata approach with an infinite sample.
} 
system to test for global optimality. This lack of standards to report nonconvex results as well as the need to go beyond traditional convex optimisation that is often considered a cornerstone for economic analysis may well contribute to its negligence.

\section{References}

Afriat, S. (1972): "Efficiency Estimation of Production Functions," International Economic Review, 13(3), 568-598.

Alam, I., And R. Sickles (2000): "Time Series Analysis of Deregulatory Dynamics and Technical Efficiency: The Case of the US Airline Industry," International Economic Review, 41(1), 203-218.

Allahverdi, A., C. NG, T. Cheng, and M. Kovalyov (2008): "A Survey of Scheduling Problems with Setup Times or Costs," European Journal of Operational Research, 187(3), 985-1032.

Ang, F., S. Mortimer, F. Areal, and R. Tiffin (2018): "On the Opportunity Cost of Crop Diversification," Journal of Agricultural Economics, 69(3), 794-814.

Atkinson, S., And J. Dorfman (2009): "Feasible Estimation of Firm-Specific Allocative Inefficiency Through Bayesian Numerical Methods," Journal of Applied Econometrics, 24(4), 675-697.

Badunenko, O., D. Henderson, and S. Kumbhakar (2012): "When, Where and How to Perform Efficiency Estimation," Journal of the Royal Statistical Society, 175A(4), 863-892.

Balaguer-Coll, M., D. Prior, and E. Tortosa-Ausina (2007): "On the Determinants of Local Government Performance: A Two-Stage Nonparametric Approach," European Economic Review, 51(2), 425-451.

BARnett, W. (2002): "Tastes and Technology: Curvature is Not Sufficient for Regularity," Journal of Econometrics, 108(1), 199-202.

Buørndal, M., And K. Jörnsten (2008): "Equilibrium Prices Supported by Dual Price Functions in Markets with Non-Convexities," European Journal of Operational Research, 190(3), 768-789.

Bogetoft, P., J. Tama, and J. Tind (2000): "Convex Input and Output Projections of Nonconvex Production Possibility Sets," Management Science, 46(6), 858-869.

Briec, W., K. Kerstens, and P. Vanden Eeckaut (2004): "Non-convex Technologies and Cost Functions: Definitions, Duality and Nonparametric Tests of Convexity," Journal of Economics, 81(2), 155-192.

Brokken, R. (1977): "The Case of a Queer Isoquant: Increasing Marginal Rates of Substitution of Grain for Roughage in Cattle Finishing," Western Journal of Agricultural Economics, 1(1), $221-224$. 
Budish, E., P. Cramton, and J. Shim (2014): "Implementation Details for Frequent Batch Auctions: Slowing Down Markets to the Blink of an Eye," American Economic Review, 104(5), 418-424.

Cesaroni, G., and D. Giovannola (2015): "Average-Cost Efficiency and Optimal Scale Sizes in Non-Parametric Analysis," European Journal of Operational Research, 242(1), 121-133.

Copeland, A., and G. Hall (2011): "The Response of Prices, Sales, and Output to Temporary Changes in Demand," Journal of Applied Econometrics, 26(2), 232-269.

Coviello, D., A. Ichino, And N. Persico (2014): "Time Allocation and Task Juggling," American Economic Review, 104(2), 609-623.

Cummins, D., And H. Zi (1998): "Comparison of Frontier Efficiency Methods: An Application to the U.S. Life Insurance Industry," Journal of Productivity Analysis, 10(2), 131-152.

De Borger, B., And K. Kerstens (1996): "Cost Efficiency of Belgian Local Governments: A Comparative Analysis of FDH, DEA, and Econometric Approaches," Regional Science and Urban Economics, 26(2), 145-170.

Diewert, W., and C. Parkan (1983): "Linear Programming Test of Regularity Conditions for Production Functions," in Quantitative Studies on Production and Prices, ed. by W. Eichhorn, K. Neumann, and R. Shephard, pp. 131-158. Physica-Verlag, Würzburg.

Eaton, B., And R. Lipsey (1997): On the Foundations of Monopolistic Competition and Economic Geography: The Selected Essays of B. Curtis Eaton and Richard G. Lipsey. Edward Elgar, Cheltenham.

Estache, A., M. Rossi, and C. Ruzzier (2004): "The Case for International Coordination of Electricity Regulation: Evidence from the Measurement of Efficiency in South America," Journal of Regulatory Economics, 25(3), 271-295.

Fan, Y., and A. Ullah (1999): "On Goodness-of-fit Tests for Weakly Dependent Processes Using Kernel Method," Journal of Nonparametric Statistics, 11(1), 337-360.

FÄRE, R. (1988): Fundamentals of Production Theory. Springer, Berlin.

FArrell, M. (1959): "The Convexity Assumption in the Theory of Competitive Markets," Journal of Political Economy, 67(4), 377-391.

Fuss, M., D. McFadden, and Y. Mundlak (1978): "A Survey of Functional Forms in the Economic Analysis of Production," in Production Economics: A Dual Approach to Theory and Applications, vol. 1, ed. by M. Fuss, and D. McFadden, pp. 219-268. North-Holland, Amsterdam. 
Garbaccio, R., B. Hermalin, and N. Wallace (1994): "A Comparison of Nonparametric Methods to Measure Efficiency in the Savings and Loan Industry," Real Estate Economics, 22(1), $169-193$.

Grifell-Tatjé, E., and K. Kerstens (2008): "Incentive Regulation and the Role of Convexity in Benchmarking Electricity Distribution: Economists versus Engineers," Annals of Public and Cooperative Economics, 79(2), 227-248.

GrIffin, J. (1979): "Statistical Cost Analysis Revisited," Quarterly Journal of Economics, 93(1), 107-129.

Hackman, S. (2008): Production Economics: Integrating the Microeconomic and Engineering Perspectives. Springer, Berlin.

Hackman, S., U. Passy, and L. Platzman (1994): "Explicit Representation of the TwoDimensional Section of a Production Possibility Set," Journal of Productivity Analysis, 5(2), $161-170$.

Hasenkamp, G. (1976): "A Study of Multiple-Output Production Functions," Journal of Econometrics, 4(3), 253-262.

Hung, N., C. Le Van, and P. Michel (2009): "Non-convex aggregate technology and optimal economic growth," Economic Theory, 40(3), 457-471.

Ivaldi, M., N. Ladoux, H. Ossard, and M. Simioni (1996): "Comparing Fourier and Translog Specifications of Multiproduct Technology: Evidence from an Incomplete Panel of French Farmers," Journal of Applied Econometrics, 11(6), 649-668.

Izadi, H., G. Johnes, R. Oskrochi, and R. Crouchley (2002): "Stochastic Frontier Estimation of a CES Cost Function: The Case of Higher Education in Britain," Economics of Education Review, 21(1), 63-71.

Jacobsen, S. (1970): "Production Correspondences," Econometrica, 38(5), 754-771.

Kerstens, K., And S. Managi (2012): "Total Factor Productivity Growth and Convergence in the Petroleum Industry: Empirical Analysis Testing for Convexity," International Journal of Production Economics, 139(1), 196-206.

Kerstens, K., J. Sadeghi, and I. Van de Woestyne (2019): "Convex and Nonconvex InputOriented Technical and Economic Capacity Measures: An Empirical Comparison," European Journal of Operational Research, 276(2), 699-709.

Kerstens, K., and P. Vanden Eeckaut (1999): "Estimating Returns to Scale Using Nonparametric Deterministic Technologies: A New Method Based on Goodness-of-Fit," European Journal of Operational Research, 113(1), 206-214. 
KLein, L. (1960): "Some Theoretical Issues in the Measurement of Capacity," Econometrica, 28(2), $272-286$.

Krivonozhko, V., O. Utkin, A. Volodin, I. Sablin, and M. Patrin (2004): "Constructions of Economic Functions and Calculations of Marginal Rates in DEA using Parametric Optimization Methods," Journal of the Operational Research Society, 55(10), 1049-1058.

Kumbhakar, S., and C. Lovell (2000): Stochastic Frontier Analysis: An Econometric Approach. Cambridge University Press, Cambridge.

LI, Q. (1996): "Nonparametric Testing of Closeness between Two Unknown Distribution Functions," Econometric Reviews, 15(1), 261-274.

LI, S.-K. (2019): "A Nonparametric Test of Quasiconcave Production Function with Variable Returns to Scale," Journal of Mathematical Economics, 82, 160-170.

Maddala, G., and R. Roberts (1981): "Statistical Cost Analysis Re-Revisited: Comment," Quarterly Journal of Economics, 96(1), 177-182.

Mas-Colell, A., A. Whinston, and J. Green (1995): Microeconomic Theory. Oxford University Press, Oxford.

Narbón-Perpiñá, I., M. Balaguer-Coll, M. Petrović, and E. Tortosa-Ausina (2020): "Which Estimator to Measure Local Governments' Cost Efficiency? The Case of Spanish Municipalities," SERIEs, 11(1), 51-82.

Narbón-Perpiñá, I., M. Balaguer-Coll, and E. Tortosa-Ausina (2019): "Evaluating Local Government Performance in Times of Crisis," Local Government Studies, 45(1), 64-100.

Oude Lansink, A., S. Stefanou, and M. Kapelko (2015): "The Impact of Inefficiency on Diversification," Journal of Productivity Analysis, 44(2), 189-198.

Podinovski, V. (2004a): "Efficiency and Global Scale Characteristics on the "No Free Lunch" Assumption Only," Journal of Productivity Analysis, 22(3), 227-257.

(2004b): "Local and Global Returns to Scale in Performance Measurement," Journal of the Operational Research Society, 55(2), 170-178.

Preckel, P., And T. Hertel (1988): "Approximating Linear Programs with Summary Functions: Pseudodata with an Infinite Sample," American Journal of Agricultural Economics, 70(2), 397402.

RAY, S. (1997): "Weak Axiom of Cost Dominance: A Nonparametric Test of Cost Efficiency Without Input Quantity Data," Journal of Productivity Analysis, 8(2), 151-165.

(2004): Data Envelopment Analysis: Theory and Techniques for Economics and Operations Research. Cambridge University Press, Cambridge. 
RAY, S., ANd H. KIm (1995): "Cost Efficiency in the US Steel Industry: A Nonparametric Analysis using Data Envelopment Analysis," European Journal of Operational Research, 80(3), 654-671.

RaY, S., And K. MukherJee (1995): "Comparing Parametric and Nonparametric Measures of Efficiency: A Reexamination of the Christensen-Greene Data," Journal of Quantitative Economics, 11(1), 155-168.

Resti, A. (1997): "Evaluating the Cost-Efficiency of the Italian Banking System: What Can Be Learned From the Joint Application of Parametric and Non-Parametric Techniques," Journal of Banking \& Finance, 21(2), 221-250.

Romer, P. (1990): “Are Nonconvexities Important for Understanding Growth?," American Economic Review, 80(2), 97-103.

SAuer, J. (2006): "Economic Theory and Econometric Practice: Parametric Efficiency Analysis," Empirical Economics, 31(4), 1061-1087.

Savani, R. (2012): "High-Frequency Trading: The Faster, the Better?," IEEE Intelligent Systems, $27(4), 70-74$.

ScArf, H. (1986): "Testing for Optimality in the Absence of Convexity," in Social Choice and Public Decision Making: Essays in Honor of Kenneth J. Arrow, Volume I, ed. by W. Heller, R. Starr, and S. Starrett, pp. 117-134. Cambridge University Press, Cambridge.

(1994): "The Allocation of Resources in the Presence of Indivisibilities," Journal of Economic Perspectives, 8(4), 111-128.

Shephard, R. (1970): Theory of Cost and Production Functions. Princeton University Press, Princeton.

VArian, H. (1984): "The Nonparametric Approach to Production Analysis," Econometrica, 52(3), $579-597$.

Viton, P. (2007): "Cost Efficiency in US Air Carrier Operations, 1970-1984: A Comparative Study," International Journal of Transport Economics, 34(3), 369-401.

Wibe, S. (1984): "Engineering Production Functions: A Survey," Economica, 51(204), 401-411.

Winter, S. (2008): "Scaling Heuristics Shape Technology! Should Economic Theory Take Notice?," Industrial and Corporate Change, 17(3), 513-531. 